\title{
Francisco Prieto. Un pintor en la docencia
}

\author{
Fernando Pérez Mulet \\ Catedrático de Universidad de Historia del Arte. Departamento Historia Moderna, \\ Contemporánea, de América y del Arte de la Universidad de Cádiz. \\ fernando.mulet@uca.es \\ ORCID: http://orcid.org/0000-0002-2492-7295
}

RESUMEN: En 1917 toma posesión de su plaza de Profesor Especial de Dibujo en la Escuela Normal de Maestros de Cádiz el pintor vallisoletano Francisco Prieto Santos, plaza y dedicación que no abandonará hasta su jubilación en 1954. En este tiempo, interrumpido brevemente por los años de la Guerra Civil, entre la docencia y el ejercicio libre de la pintura, este castellano se vinculará plenamente a la vida de Cádiz y a la imagen de Andalucía.

Palabras Clave: Profesor, Dibujo, Pintura, Cádiz, Francisco Prieto Santos.

\section{Francisco Prieto. A painter in teaching}

ABSTRACT: In 1917, the Valladolid painter Francisco Prieto Santos takes possession like a Special Drawing Professor at the Normal School of Teachers of Cádiz, a position and dedication that he will not leave until his retirement in 1954. At this time, briefly interrupted by the years of the Civil War, between teaching and the free exercise of painting, this castilian will be fully linked to the life of Cádiz and the image of Andalusia.

Keywords: Professor, Drawing, Painting, Cádiz, Francisco Prieto Santos.

Aún ignoro, al día de hoy, en qué momento, lugar y circunstancias Francisco Prieto Santos, mesetario de Valladolid, cayó en la cuenta de que ser de pueblo era un don de Dios y que ser de ciudad era un poco como ser inclusero aunque, intuyo, debió alcanzar tal clarividencia bastante antes que el Isidoro de las viejas historias de Castilla la Vieja, esas que narraría generaciones después su paisano Delibes, porque mientras el pueblo permanecía, la ciudad se desintegraba por aquello del progreso y las perspectivas de futuro.

Sí vengo en sostener que no fue el azar sino la conveniencia propia, por conocimiento anterior o por noticias y elogios recibidos, bien por conocidos, bien a través de los medios de su época, la que le emplazó con preferencia en Andalucía. Aunque, tal vez, fuera porque su padre, natural de Carmona, le ponderase las excelencias meridionales. Es el caso, en fin, que sus andanzas previas a la madurez terminarían en la que considero la ciudad urbana por 
excelencia, un arca flotando entre las aguas, antítesis de lo rural que no de lo popular, que era por entonces Cádiz. Pero esto no sucedió sino en 1917, cuando Prieto ya frisaba los 33 años. En el camino quedaban estancias, estudios y experiencias entre Madrid y París sin ningún género de duda, América pudiera ser, no siempre documentadas y, al igual que ocurría con otros paisanos pintores de su generación en Valladolid, tan notables como Aurelio García Lesmes o Anselmo Miguel Nieto, todavía con la buena perspectiva de una carrera profesional por consolidar y de la que mantenerse y disfrutar. ${ }^{1}$

Existen, no obstante, hechos ciertos y, mejor aún, datos fehacientes, en especial los documentales que, pese a la seca frialdad de su concreción, permiten articular una trayectoria no solo administrativa sino vital en toda su amplitud. De esta es su carrera docente la que ahora nos va a ocupar pero, en buena lógica y de resultas, la doble vertiente artística y, en su justa medida, biográfica se irán revelando al mismo tiempo. De estos datos, los puramente de despacho pues, pretenden tratar estas páginas. En ello, centrados fundamentalmente en su expediente personal, el conservado en el Archivo Histórico de la Universidad de Cádiz, ${ }^{2}$ y apoyados en los otros registros que se intercalan a lo largo de su dilatada carrera, articularemos esta faceta sustancial en la trayectoria vital del vallisoletano. Por supuesto, en cuanto instrumentos burocráticos, los valores primarios, cuya información no siempre tiene por qué responder al detalle o a la fiabilidad pretendida, pierden hoy interés y función frente a los secundarios, ${ }^{3}$ los que aportan pistas acerca de los valores culturales e históricos que, por supuesto, apuntalan su biografía y, por su contenido testimonial, los rasgos y circunstancias del tiempo y lugar que le tocó vivir.

Los primeros datos que constan en dicho expediente son los propios de la expedición del título de Profesor Especial de Dibujo y la toma de posesión de su plaza gaditana, ambos llevados a cabo en Madrid en 5 y 12 de julio de 1917 respectivamente. A estos se le adjunta un certificado médico de padecimiento de gastritis, firmado por el médico titular en la localidad palentina de Barruelo, ${ }^{4}$ afección que le impedía «dedicarse a las ocupaciones habituales»y, en consecuencia, incorporarse tempranamente a la Escuela Normal de

\footnotetext{
${ }^{1}$ Para un conocimiento completo de la vida y obra del pintor, tanto en Cádiz como en Valladolid, que damos por entendido a lo largo del texto, véanse PÉREZ Mulet, FERnANDO. El pintor Francisco Prieto Santos. Vida y obra, Diputación de Cádiz, Cádiz, 1979. Brasas EgIDO, José Carlos y URREA Fernández, Jesús. Pintura y escultura en Valladolid en el siglo XX (1900-1936), Ateneo de Valladolid, Valladolid, 1988. URREA, JESÚS. Patrimonio y coleccionismo de la Diputación de Valladolid. En: Historia, Paisaje y Figura. Mecenazgo y coleccionismo de la Diputación de Valladolid, Diputación de Valladolid, Valladolid, 2017. pp. 10 y 26.

${ }^{2}$ Archivo de la Universidad de Cádiz (AUCA). C-102-17 EN. Expediente personal de Francisco Prieto Santos. Escuela Normal de Cádiz. Se entiende que, a lo largo del texto, cuando no hay llamadas o notas a pie, hacemos uso del expediente en cuestión. Véase al respecto RAMOs SANTANA, AlberTo. Los fondos históricos del Archivo de la Universidad de Cádiz: bastante más que historia de la universidad. Cuadernos de Investigación de Fondos del Archivo UCA. N. ${ }^{\circ}$ 1. 2019. p. 47. Disponible en: https://revistas.uca.es/index.php/cifa/issue /view/360.

3 «De la consideración del valor primario y secundario se desprende la división de los Archivos en Administrativos e Históricos [...]. El valor administrativo es inherente al documento hasta tanto el testimonio escrito engendre derechos y obligaciones y sirva de garantía para justificar situaciones y hechos, es paralelo a la vigencia administrativa y va perdiéndose con el paso del tiempo». HEREDIA HerRerA, ANTONIA. Archivística General. Teoría y Práctica, Diputación de Sevilla, Sevilla, 1987, p. 97.

${ }^{4}$ Barruelo de Santullán. Esta población, con una destacada actividad minera del carbón, era por entonces el lugar de residencia de sus padres. Referencia oral de José María Prieto Soler, hijo del artista.
} 
Maestros y Maestras de Cádiz. Sin embargo, antes del comienzo oficial del curso ya se encuentra en la ciudad y a plena disposición del Centro. ${ }^{5}$

Figura 1. La hoja de servicios o carrera artística

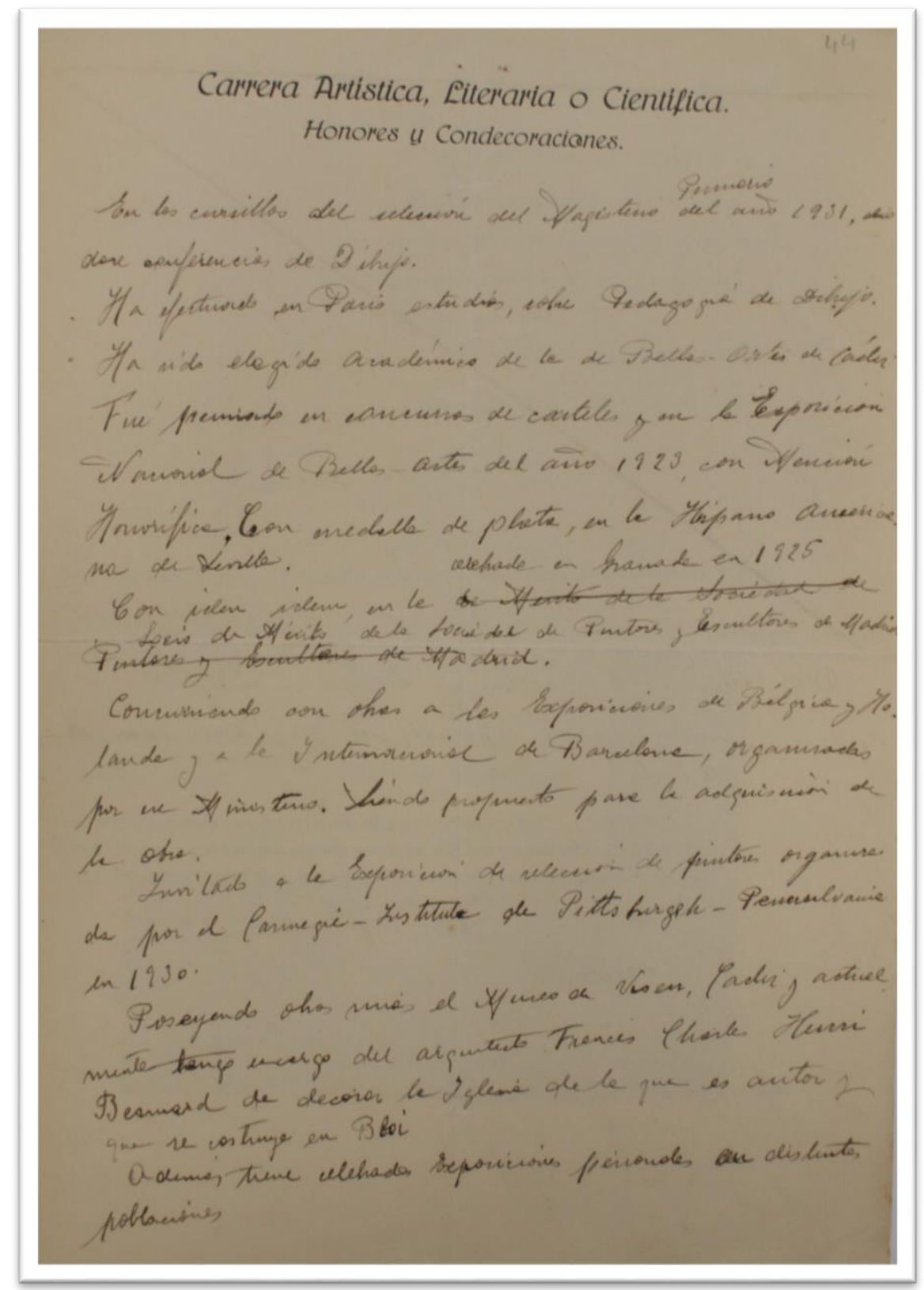

Fuente: Archivo de la Universidad de Cádiz (AUCA)

Es necesario, empero, volver atrás y atender a la convocatoria de «las oposiciones para provisión de las plazas de Profesores especiales de Educación física, Caligrafía, Francés y Dibujo de las Escuelas Normales de Maestros y Maestras» por Real Orden de 27 de julio de 1914, publicada el 6 de enero de 1915 y, después, el 8 de agosto con la agregación de más

\footnotetext{
${ }^{5}$ El 25 de septiembre de 1917 asiste por primera vez al claustro de la Normal de Maestros. En el acta se hace constar los nuevos nombramientos de quienes «han ganado las plazas en reñidas oposiciones y son una esperanza para nuestra Escuela». AUCA. Libro de actas de sesiones del Claustro de la Escuela Normal de Maestros, 1914/1931. L-3 EN.

DOI del artículo:

https://doi.org/10.25267/Cuad investig fondos arch UCA.2020.i2.07 
plazas, Cádiz entre ellas. ${ }^{6}$ A estas, que obedecían a la nueva planificación de las enseñanzas del magisterio, ${ }^{7}$ el «Plan Bergamín», concurrirán Prieto y muchos candidatos más con la prudente intención de optar por la docencia a cambio de un sueldo fijo, respetable para la época, de inicio 1.500 pesetas anuales, y la estabilidad de un destino en capital de provincia o ciudad importante, de los 43 ofrecidos, en propiedad. En febrero del año siguiente se publican las normas de examen. Centradas en cuatro ejercicios eliminatorios, la excesiva duración de los mismos y el elevado número de concursantes, 164 en el primer ejercicio, provocará que la lista de aprobados con sus respectivos destinos, Francisco Prieto y Cádiz entre ellos, se haga pública, por Real Orden del 5 de julio, en una tardía fecha del mes de julio de $1917,{ }^{8}$ lo cual viene a concordar plenamente con los datos del expediente en cuestión.

Las pruebas consistieron, de acuerdo con el reglamento vigente de 1910 para Escuelas Normales y las disposiciones propias de las cátedras de Dibujo, así como por la Real Orden de $1914,{ }^{9}$ en cuatro ejercicios eliminatorios. El primero, escrito, respondería a un tema de geometría plana y otro de elementos de anatomía; el segundo, «copiar del yeso al claroobscuro, en tamaño académico, un fragmento ornamental.» El tercero consistiría en la contestación oral durante una hora a seis temas, a saber, dos de geometría descriptiva, dos de perspectiva y otros dos de elementos de topografía, «sacados del cuestionario á la suerte». El cuarto, último y decisivo, era un ejercicio práctico en el que, además de la copia de una estatua «en yeso», había que desarrollar un trazado lineal en proyecciones y perspectiva de un objeto corpóreo y copiar, al tiempo que explicar por escrito, un plano topográfico. ${ }^{10}$

De tales pruebas, muy atractivas en el momento para esta materia y las primeras que tuvieron lugar en las Escuelas Normales tras su reciente reforma de estudios, se deduce el sólido componente, tanto artístico cuanto técnico, que conllevaban las mismas aunque ello no pareciese valorar o expresar con rotundidad las orientaciones pedagógicas que, más tarde, se impondrían en estas pruebas y en la formación para la designación de futuros maestros. ${ }^{11}$ Así, si todo artista sabe dibujar, quién con mejor capacidad para enseñar a dibujar. El hecho ${ }^{6}$ Ministerio de Instrucción Pública y Bellas Artes. Dirección General de Primera Enseñanza. Reales Órdenes
de 23 de diciembre de 1914 y 27 de julio de 1915 en Gaceta de Madrid de 6 de enero de 1915 y de 9 de agosto
de 1915 respectivamente.
7 Ídem, Real Decreto de 30 de agosto de 1914 en Gaceta de Madrid de 2 de septiembre de 1914.
${ }^{8}$ Gaceta de Madrid de 12 de julio de 1917.
9 «Consignada ya en los presupuestos del Estado la dotación para las plazas de Profesores especiales de los
estudios del Magisterio que antes carecían de ella, ha llegado la hora de que dichas plazas puedan proveerse
mediante oposición, conforme determina el artículo 48 del Real decreto de 30 de agosto de 1914 [...]. Dentro
de la primera decena de Enero próximo se anunciarán por la Dirección General de Primera enseñanza las
oposiciones [...]. Cuando existan dos Escuelas Normales en una misma localidad habrá un solo Profesor para
la enseñanza de cada una de dichas asignaturas en ambas Normales [...]. Tanto las condiciones exigidas á los
aspirantes como los ejercicios de oposición á las clases de Caligrafía, Francés y Dibujo, serán los mismos que
establece la ley vigente para las oposiciones á Cátedras de enseñanzas iguales de los Institutos generales y
técnicos [...]. Es asimismo voluntad de S. M. que se den las gracias en su nombre á las Profesoras y Profesores
interinos que con carácter gratuito y demostrando con ello su amor á la enseñanza, han venido hasta aquí
desempeñando en las Escuelas Normales las clases de asignaturas especiales á que se refieren los párrafos ante-
riores...» Real Orden de 28 de diciembre de 1914 en Gaceta de Madrid de 31 de diciembre de 1914.
10 Gaceta de Madrid de 7 de febrero de 1916.
${ }_{11}^{11}$ MolERo PINTADO, ANTONIO. La formación del maestro español, un debate histórico permanente, Revista de
Educación, núm. extraordinario (2000), pp. 63-66.

DOI del artículo:

https://doi.org/10.25267/Cuad investig fondos arch UCA.2020.i2.07 
es que el tribunal estuvo conformado por cuatro artistas prestigiosos en sus respectivas carreras. Eran, pues, José Esteban Lozano, Juan Antonio Benlliure, José Blanco y Coris y Arturo Somozas de Armas, siendo estos dos últimos profesores de Escuela de Artes y Oficios lo que, de resultas, les situaba en un nivel adecuado para dirimir las exigencias de las plazas. $^{12}$

Por añadido y observando la lista completa de aspirantes, la nómina de artistas, más o menos jóvenes, que ya habían destacado para la crítica en el período y que concurren se hace aquí poco menos que abultada. Así, consiguieron plaza junto a Prieto Santos, entre otros, Francisco Esteve Botey en Barcelona, Félix Lacárcel Aparici en Sevilla, ${ }^{13}$ Hermenegildo Lanz en Granada, Antonio Martínez Virel en Málaga, Eduardo Bádenes del Sacramento en Córdoba e Ignacio Pinazo Martínez, hijo del célebre Pinazo Camarlench, en Albacete. Gabriel García Maroto firma igualmente la oposición. Además, entre los excluidos por diferentes razones de índole formal, encontramos también a Adelardo Covarsí, Eulogio Varela y Sartorio, Eugenio Gómez Mir, Ricardo Estivill y de Llorach, María Gutiérrez Blanchard y Fernando Labrada. El mismo Prieto fue inicialmente excluido por presentar la instancia fuera de plazo. ${ }^{14}$

Sintomático, por último, es encontrarnos fuera de la lista de aprobados a los aspirantes Alberto Blanco Roldán y Elisa López Velasco, docentes también en fecha más tardía, con una posterior destacada proyección especialmente teórica y pedagógica, que concebirían la docencia del dibujo en calidad de medio de conocimiento y herramienta de aprendizaje, un útil fundamental para cualquier otra disciplina, y no necesariamente como una metodología con la exclusiva finalidad plástica de formar artistas. ${ }^{15}$

Hay que esperar a 1920, en mayo, para obtener nuevos datos. En estos, al tiempo que se observa su primera confirmación como profesor del centro con la consecuente subida de sueldo a 4.000 pesetas anuales y efectos del 1 de abril, contemplamos sus únicos pormenores militares, cual el de su licencia total, dada en Valladolid a 31 de julio de 1916, junto con un certificado de soltería, y el saberse que fue excedente de cupo en el reemplazo de 1904.

Constan además títulos y quinquenios varios así como dos hojas de servicios, una de ellas hasta 1934 y en la que expone de su propia mano los honores y méritos contraídos hasta el momento. Finalmente, con el advenimiento de la República, desde 1931 pasará a denominarse profesor de la Escuela Normal del Magisterio Primario de Cádiz al haberse unificado ambas anteriores de Maestros y Maestras en el ambicioso plan renovador nacional de la educación. ${ }^{16}$ Ya en 1933, tras la reforma de los planes de estudios para la Segunda Enseñanza, se le emitirá un informe favorable para desempeñar, mediante la correspondiente gratificación de honorarios, la plaza de profesor de la recién implantada nueva enseñanza de Dibujo. Dicho informe será la pieza concluyente para que, convocado el pertinente concurso

\footnotetext{
${ }^{12}$ Gaceta de Madrid de 19 de noviembre de 1915.

${ }^{13}$ Sin constatación documental, de momento, podemos afirmar que Prieto y Lacárcel permutarían o llegarían al acuerdo en optar uno por Cádiz y el otro por Sevilla. Referencia oral de José María Prieto.

14 Ídem.

15 Véase CuENCA EsCRIBANO, ANTONIO. El dibujo en la escuela. Una revisión histórica de sus primeros tratadistas. Tendencias Pedagógicas, 14. Portal de Revistas Electrónicas UAM. Madrid, 2009. pp. 335-345.

${ }^{16}$ Gaceta de Madrid de 30 de octubre de 1931.
} 
público de provisión de la plaza, le sea otorgada en detrimento del otro más que dotado aspirante, en su calidad de docente de la Escuela de Artes e Industrias local, el prestigiado y ya longevo arqueólogo y director del Museo Provincial Pelayo Quintero Atauri. ${ }^{17}$ Así, desde octubre de 1934, ${ }^{18}$ también quedará incorporado al claustro de profesores del Instituto Nacional de Segunda Enseñanza de Cádiz, es decir, el tradicionalmente conocido como Instituto Columela. ${ }^{19}$

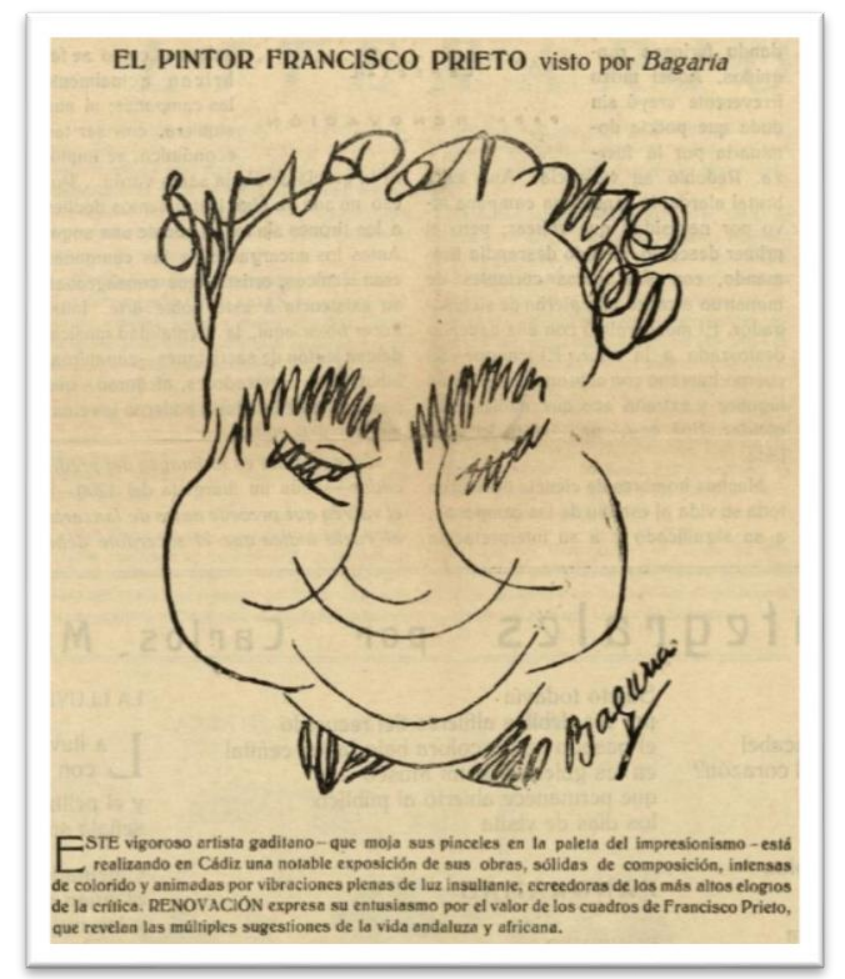

Fuente: Renovación, n. ${ }^{\circ}$ 3, revista mensual ilustrada. Cádiz, diciembre 1927

\footnotetext{
17 «En el concurso para provisión de la plaza de Profesor de Dibujo del Instituto Nacional de Segunda enseñanza de Cádiz, para ser acumulada a Profesor de Escuela Normal o de Artes e Industrias que dispone la Orden de 18 de Junio de 1918, el Consejo Nacional de Cultura ha emitido el siguiente dictamen: «Resulta que de todos los señores que solicitan tomar parte en el concurso, solamente dos, los Sres. Prieto y Quintero, pueden considerarse dentro de las condiciones señaladas en el anuncio del concurso, debiendo ser eliminados los Auxiliares, ya que éste se celebra entre Profesores numerarios. Ambos Sres. Prieto Santos y Quintero Atauri declaran ser autores de varias obras que no acompañan al expediente: Considerando que el Sr. Prieto Santos ingresó por oposición directa mientras el Sr. Quintero lo hizo por concurso, El Consejo, de acuerdo con el parecer expuesto por el Negociado y la Sección, del Ministerio, dictamina que procede acumular la plaza de Profesor de Dibujo del Instituto Nacional de Segunda enseñanza de Cádiz a don Francisco Prieto Santos». Y este Ministerio, conformándose con el preinserto dictamen, se ha servido resolver como en el mismo se propone. Lo que comunico a V. I. para su conocimiento y efectos». Orden de 13 de septiembre de 1934 en Gaceta de Madrid de 20 de septiembre de 1934.

${ }^{18}$ El 6 de octubre de 1934 es recibido en el claustro docente junto con el nuevo catedrático de Literatura. Archivo Histórico Provincial de Cádiz (AHPC), Instituto de Enseñanza Secundaria «Columela», Libro de Actas 1911-1937, AHP 5310.

19 Para la historia del Centro, con los sucesivos planes de estudios, véase PeTtEnGHI LACHAMBre, JosÉ ANTONIO. El Instituto “Columela” 1863-1988. 125 años de Enseñanza Secundaria en Cádiz, Cádiz, 1988. 
No obstante, por cuanto puede intercalarse con su actividad artística libre, interesa más de dicha documentación la relación de licencias y bajas por enfermedad concedidas, asî como otros permisos solicitados. En el primer caso constan cinco bajas en septiembre, tres en Arcos, una en Ubrique y otra sin determinar, en 1923, 1925, 1926, 1927 y 1928. En otro caso, abril de 1928, solicita una semana para visitar a un médico en Sevilla. ¿Eran problemas reales de salud o agotamiento por exceso de trabajo estival en su pintura? Es aquí donde el documento pierde ese sustancial carácter primario de fiabilidad y juega con las posibles intuiciones. Ciertamente, la baja de 1923, firmada por el médico titular de Arcos de la Frontera y buen amigo suyo, Rafael Benot y Rubio, viene a coincidir con el nacimiento de su primogénito pero, no menos, sin ataduras administrativas, es solo en los meses estivales cuando puede dedicarse a la pintura con plena libertad y total dedicación. Casi se podría afirmar que luz y verano conformaron un par característico indisoluble de su estilo.

En cuanto a la de 1928 hay coincidencia con su presencia en la Exposición de Primavera celebrada en Sevilla. Empero, de ello solo llegamos a deducir una entregada dedicación a la Escuela y, más tarde, al Instituto, con una carga lectiva que alcanzaba de lunes a sábado sin interrupción y es que, en efecto, el citado número de licencias por enfermedad es prácticamente inexistente a lo largo de su prolongada vida académica. Hay, por último, que hacer mención de que, como profesor de la Escuela, también colaboró en las actividades académicas y docentes que, durante su corta existencia, la aneja Residencia Normalista de Cádiz desarrolló con todo éxito. ${ }^{20} \mathrm{Y}$, por demás, es aquí, al respecto de la Residencia, donde consta una única fricción en el seno del claustro de la Escuela por causa de negárseles a los Profesores Especiales voz y voto. Prieto, en sus reiteradas demandas de que siempre han debido ser citados, dada su insistencia en no aceptar las razones legales esgrimidas, terminará siendo reconvenido por el Director y, por cuanto el motivo de la disputa estribaba en el carácter de la titulación requerida, no sin que lograra hacer constar en acta que él también tiene su título. ${ }^{21}$

Meridiano, por el contrario, es el permiso solicitado y concedido expresamente para girar una prolongada visita a las Exposiciones Iberoamericanas de Sevilla y Barcelona a comienzos de 1930. Aún así, al término de la licencia concedida, la directora de la Escuela de Maestras preguntaría a su homónimo de la de Maestros si ya se había reintegrado a su puesto, por lo que parece que a un centro volvió antes que al otro. Sí es evidente la actividad desplegada en esta década en lo que a su pintura respecta. Es cuando su estilo queda, en todas sus facetas, cristalizado de por vida: luz, color y temática regionalista, Andalucía, olvidada ya Castilla, los paisajes y tipos de la sierra gaditana y del verano transcurrido en Tetuán y, de por medio, la urbe, Cádiz y, frente a su vivienda y estudio, su Alameda. Pero esto ya conduciría a otro relato, el de su vocación por lo popular, por el campo, la sierra y sus gentes, en esencia su visión de Andalucía, y la pasión por Arcos de la Frontera.

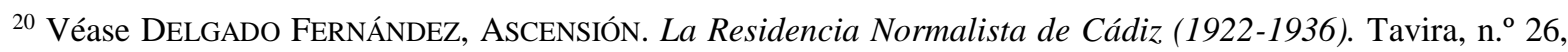
Cádiz, 2010.

${ }^{21}$ Sesiones de 28 de febrero y 27 de marzo de 1925. AUCA. L-3 EN.

DOI del artículo:

https://doi.org/10.25267/Cuad investig fondos arch UCA.2020.i2.07 
Figura 3. Francisco Prieto. Ubrique. 1935

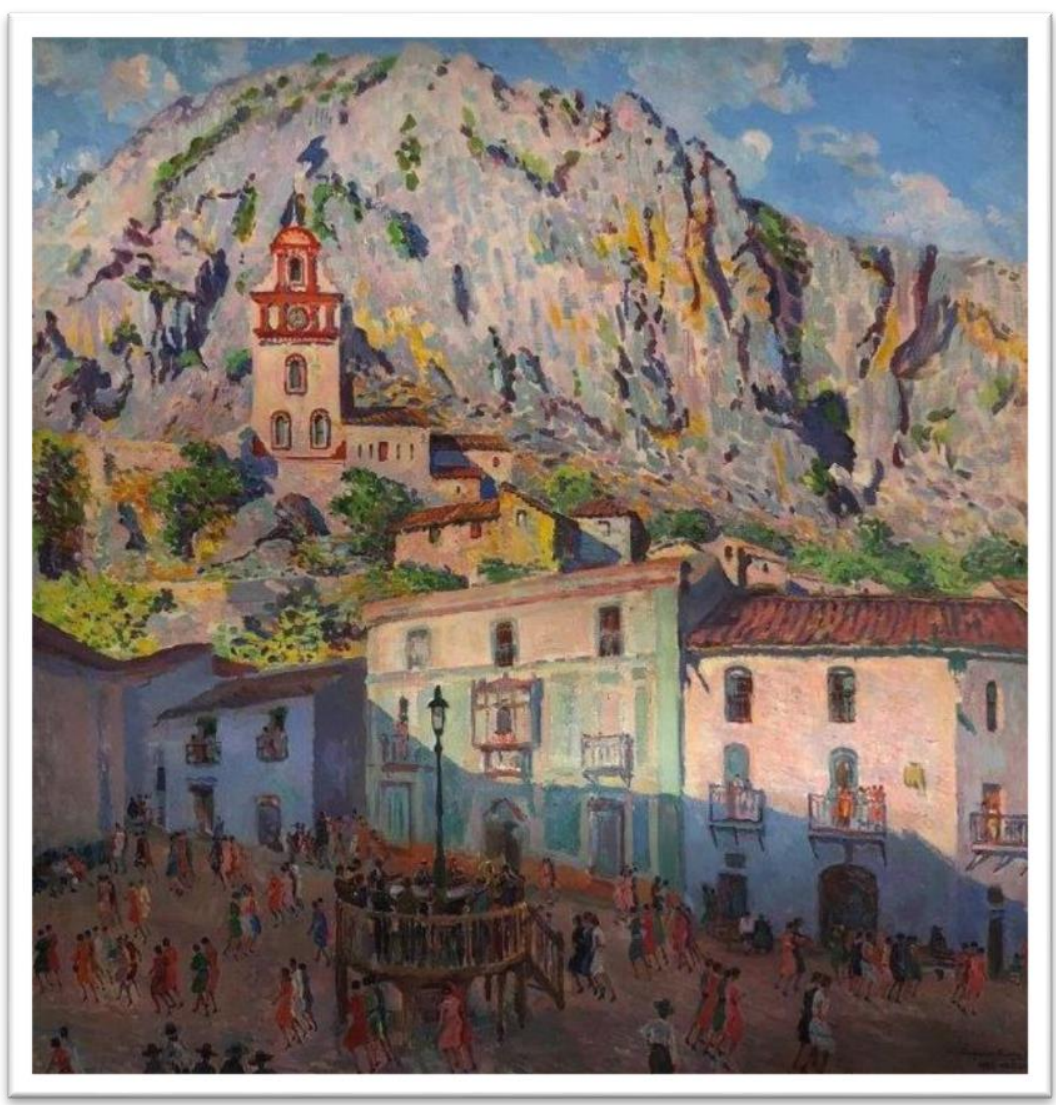

Fuente: Colección particular. Sevilla

Figura 4. Francis Harburger. Estudio con dedicatoria. París, 1930

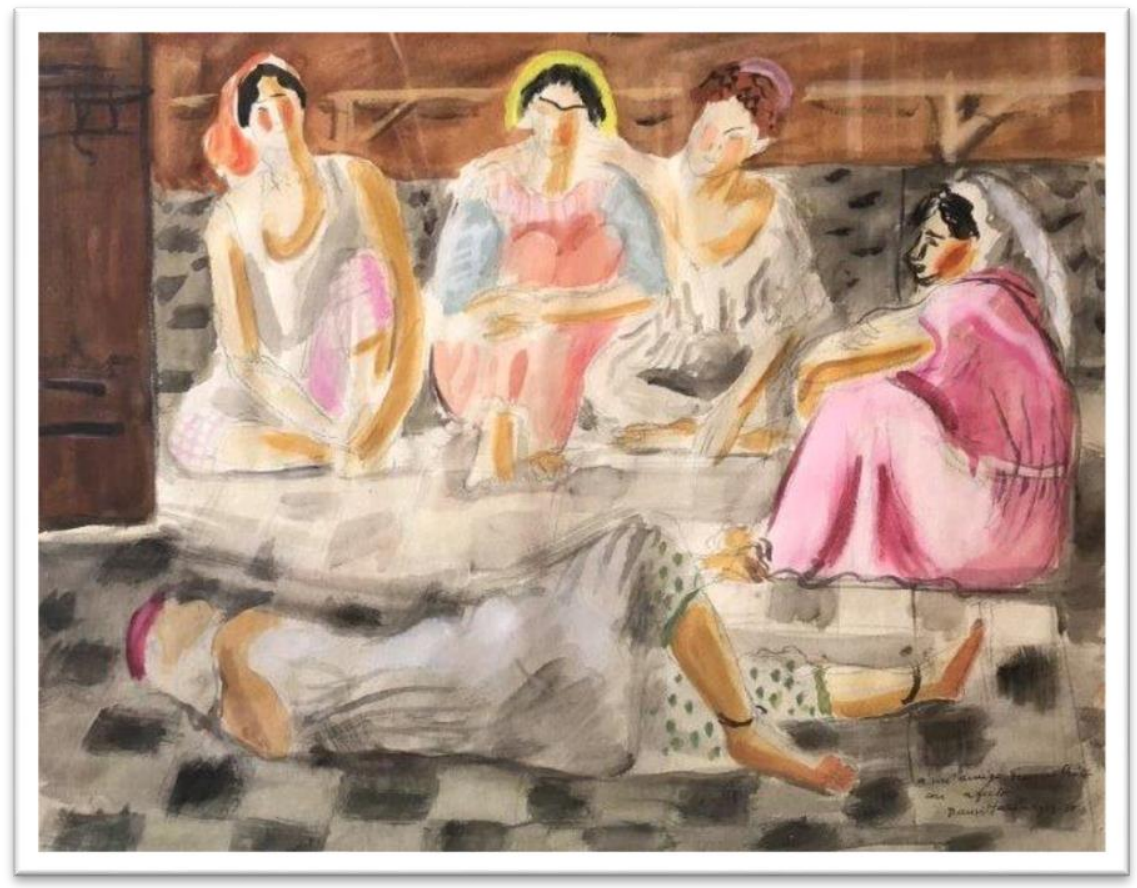

Fuente: Colección particular. Sevilla

DOI del artículo:

https://doi.org/10.25267/Cuad investig fondos arch UCA.2020.i2.07
Editorial UCA

REVISTAS | Universidad de Cádiz 
Igualmente interesa observar de su Hoja de Servicios de la Escuela Normal, con término en 1934, en la página correspondiente a sus méritos o «Carrera Artística», dos singularidades. Por una parte, la alusión a estudios de pedagogía del dibujo recibidos en París, sin más detalles, y su contribución como conferenciante a los cursillos de selección ${ }^{22}$ del magisterio primario de 1931, tarea procedente al ser un miembro permanente del claustro de la Escuela. ${ }^{23}$ Son estas las únicas referencias escritas que podemos observar al presente acerca de su vertiente profesional de educador. Por otra, al aludir al «encargo del arquitecto francés Charles Henri Besnard de decorar la Iglesia de la que es autor y que se construye en Bloi», nos está dando testimonio de su relación con el vecino país, no ya de la vivida previamente, sino de la que, al presente, vino a disfrutar.

En efecto, dicha iglesia, ${ }^{24}$ adscrita a un convento de frailes capuchinos, fue proyectada inicialmente por este destacado arquitecto pero, comenzadas las obras en 1932, se interrumpieron en 1935 y sería otro arquitecto, Paul Rouvière, sin relación alguna con Francisco Prieto, quien continuara su construcción. La realidad es que, además de su amistad con artistas españoles de su generación, Aurelio Arteta, Fernando Labrada o Eugenio Hermoso entre otros muchos, también mantuvo una excelente relación ${ }^{25}$ con Francis Harburger, judío francés natural de Orán, a quien inicialmente pudo conocer, bien en Madrid, en su condición de primer becario en España de la Casa de Velázquez en 1928, ${ }^{26}$ bien directamente en París. Ambos, al margen de su sintonía personal, venían a coincidir como pintores en su pasión por la temática magrebí en toda su riqueza humana y cromática. En cualquier caso, sí resulta evidente dicha relación con el vecino país que, tan someramente, dejó entrever en sus hojas de servicios. ${ }^{27}$

No puede completarse su biografía sin hacer mención de algo que, pese a su carácter episódico y como al resto de los españoles, trastornó significativamente su existencia y, tangencialmente, a su estilo. En julio de 1936, hallándose en Madrid con motivo de la Exposición Nacional de Bellas Artes, queda aislado de su hogar y lugar de trabajo. Al margen, pues, de las noticias orales conseguidas, recuerdos básicamente, sus incidencias hay que localizarlas, de momento al menos, en las páginas de la Gaceta de Madrid y la subsiguiente Gaceta de la República. Así, el plan de trabajo que tan diligentemente se había aprobado en junio y del que consta que se haría cargo como en cursos anteriores del

\footnotetext{
22 Se sustituyeron las oposiciones, consideradas inadecuadas, por un procedimiento más acorde con una pedagogía actualizada y que se fundamentaba en los denominados «cursillos de selección profesional». Gaceta de Madrid de 4 de julio de 1931.

${ }^{23}$ Véase BENVENUTy MORALES, JuAN. Educación y política educativa en Cádiz durante la Segunda República (1931-1936). Cádiz, 1987.

${ }^{24}$ Basilique Notre-Dame de la Trinité en Blois. Véase: https://archiwebture.citedelarchitecture.fr/fonds.

${ }^{25}$ Referencia oral de José María Prieto Soler.

26 Delaunay, Jean-Marc. Des Palais en Espagne. L'École des hautes études hispaniques et la Casa de Velázquez au coeur des relations franco-espagnoles du XX Siècle (1898-1979). Casa de Velázquez, Madrid, 1994. p. 237.

27 En su Hoja de Servicios del Instituto, firmada en junio de 1936, en la relación de exposiciones internacionales a las que ha concurrido, cita expresamente «París Casa Velazquez». AHPC, Instituto de Enseñanza Secundaria «Columela», legajo 30538, Expediente 40, Francisco Prieto Santos.

DOI del artículo:

https://doi.org/10.25267/Cuad investig fondos arch UCA.2020.i2.07 
seminario de Arte no lo iba a poder cumplir. ${ }^{28}$

En dichas páginas, consecutivamente, vamos a encontrarnos con su asimilación al escalafón de Catedráticos de Institutos de Enseñanza Media, en octubre de 1936, en los meses que subsiste entre amigos en Madrid, incomunicado con Cádiz, zona nacional, no por haber participado en los «cursos prácticos de perfeccionamiento y selección del profesorado de Segunda enseñanza» de 1933, principal razón en gran parte de estos nombramientos, sino en su calidad de Profesor Especial de Dibujo desplazado inoportunamente de su centro oficial. $^{29}$

Figura 5. Francis Harburger (1905-1998). Apunte de Francisco Prieto con dedicatoria. París, 1930

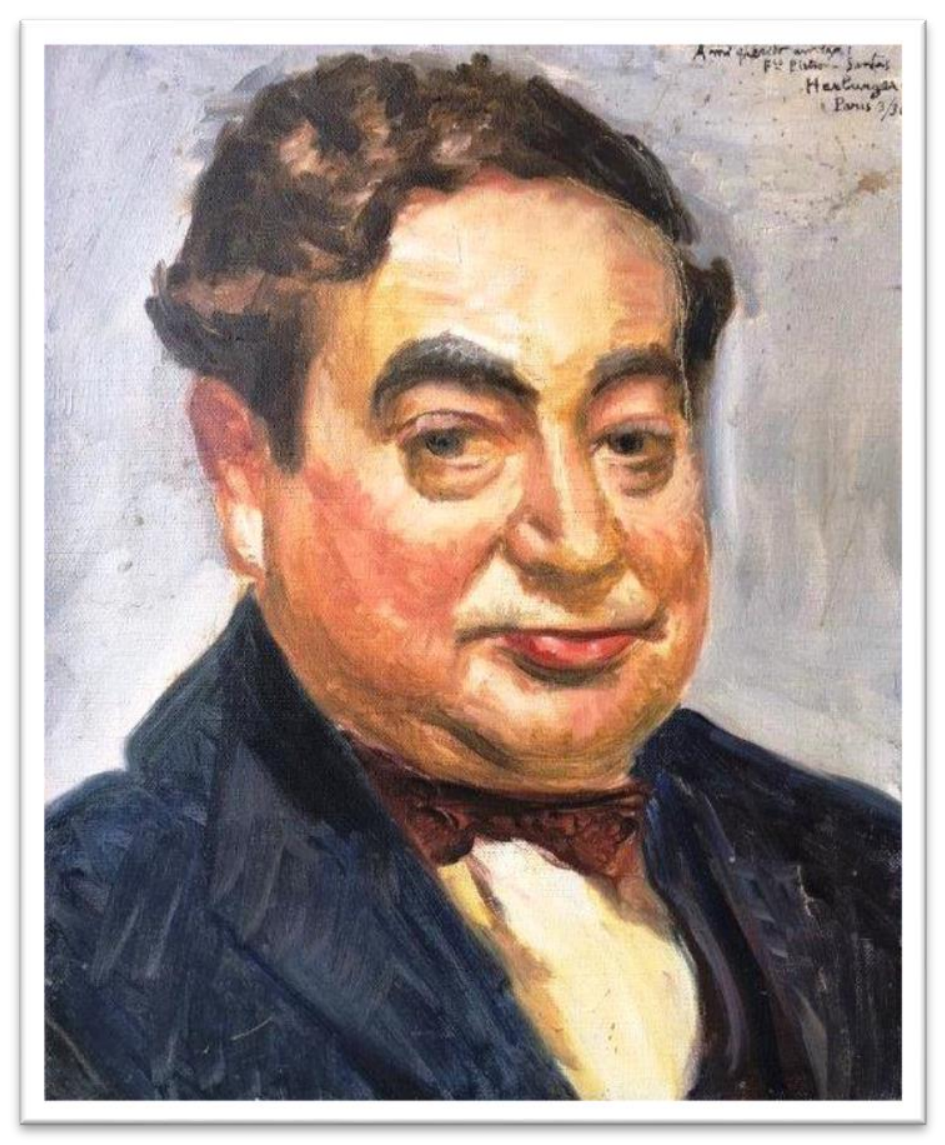

Fuente: Colección particular. Sevilla

Es una situación similar a la del joven y afamado cartelista Rafael de Penagos, y en uno y otro caso la incorporación definitiva tendrá lugar en septiembre de 1938. Conviene recordar que, como profesores encargados de curso provenientes de dichos cursos de 1933, se encontraban Timoteo Pérez Rubio, Enrique Climent, Antonio Rodríguez Luna o Alberto Sánchez, todos ellos figuras destacadas y activamente incursas en las corrientes de renovación estética e ideológica del arte español del período.

En todo caso, entre los iniciales meses de desorden propios de la guerra y los procesos de reorganización, para su vuelta efectiva a la docencia tuvo que esperar a septiembre de

${ }^{28}$ Sesión de 18 de junio de 1936. AUCA. Libro de actas de sesiones del Claustro de la Escuela Normal, 19311938. L-5 EN.

${ }^{29}$ Gaceta de Madrid de 4 de octubre de 1936.

DOI del artículo:

https://doi.org/10.25267/Cuad investig fondos arch UCA.2020.i2.07 
1937. Es entonces destinado a la Escuela Normal de Cuenca. ${ }^{30}$ Debiendo haberse incorporado con antelación, pues su nombramiento es de 22 de mayo, se le abre expediente de acuerdo al vigente artículo 171 de la «ley Moyano», ${ }^{31}$ siendo sobreseída la causa y tras quedar supuestamente demostrada su no desafección a la República. ${ }^{32}$ Nada más conocemos al respecto, al margen de su incidencia formal en el estilo y limitada producción de su obra que, por demás, no solo habría que achacar a su estancia conquense sino a las influencias de los artistas y amigos de Madrid, especialmente el citado Fernando Labrada, y a la escasez de materiales de pintura. Es, desde luego, un corto período, casi un paréntesis, pero que incide en su expresión determinantemente y del que opta, poco más adelante, olvidarse.

Para el curso siguiente la reincorporación a Cádiz es inmediata y la rehabilitación, condición imprescindible, discurre sin problemas. La directora de la Escuela, María Josefa Pascual, participa al director del Instituto Columela la favorable comunicación remitida por la Dirección General de Primera Enseñanza del 10 de agosto de $1939 .^{33}$

Políticamente, pues, tanto ahora como en los años precedentes en zona republicana, al igual que gran parte de los españoles Prieto se mueve ajeno a la política pues sus convicciones no las expresa abiertamente, esto al margen igualmente del desencanto y de la necesidad vital de seguir adelante, de recuperar los años perdidos fuera del hogar. Y, por supuesto, el que su estética, para tales años, los previos y los posteriores, se confirmara en el seguimiento de la tradición frente a las nuevas propuestas plásticas de su época o de generaciones más recientes, como las de los citados cursillistas, no debe implicar su inmediata traducción a la esfera de las ideas sociales. No es esa la lectura ni en él ni en otros artistas de su tiempo.

Desde la vuelta a Cádiz, al reencuentro con la familia, las noticias documentales ya hay que continuarlas haciendo uso de su expediente del Instituto de Enseñanza Media. Entre ellas hay una donde manifiesta no haber cobrado su correspondiente gratificación del mes de marzo, por causar baja en la Escuela Normal de Cuenca, y una recopilación de oficios acreditativos en los meses siguientes a fin de regularizar su situación profesional. Según estos, al poco tiempo será ascendido por antigüedad, de «segunda categoría», en su plaza de instituto, como también le sucede al citado Rafael Penagos en Barcelona, a la gratificación

\footnotetext{
${ }^{30}$ Incorporado a su destino «Esta Dirección General ha resuelto anular la Orden de incursión en el artículo 171 de la Ley de Instrucción pública del mencionado profesor, habiendo de proceder el Director de la citada Escuela Normal a la apertura de expediente para depurar las causas a que se debió la ausencia del mismo. 1 de septiembre de 1937» en Gaceta de la República de 6 de septiembre de 1937.

31 «No habiéndose incorporado a su destino [...] nombrado por Orden de 22 de mayo último para la Escuela Normal del Magisterio Primario de Cuenca, Esta Dirección general ha resuelto declarar al citado Profesor incurso en el artículo 171 de la Ley de Instrucción Pública [...] 19 de Julio de 1937.» en Gaceta de la República de 19 de julio de 1937.

${ }^{32}$ Fue sobreseído el expediente incoado dado «que el retraso en incorporarse a su destino fue debido a acusas ajenas a su voluntad...» en Gaceta de la República de 4 de octubre de 1937.

33 «Considerando que el Sr Prieto Santos es persona de buenos antecedentes, de ideología derechista y afecto al Glorioso Movimiento Nacional- Esta Jefatura acuerda rehabilitar a don Francisco Prieto Santos en su cargo de Profesor especial de Dibujo, sin perjuicio de lo que resulte del expediente de depuración que habrá de instruírsele...» en Archivo Histórico Provincial de Cádiz, Instituto de Enseñanza Secundaria «Columela», legajo 30538, Expediente 40, Francisco Prieto Santos.

DOI del artículo:

https://doi.org/10.25267/Cuad investig fondos arch UCA.2020.i2.07 
de 6.000 pesetas anuales. ${ }^{34}$

Finalmente y previo a su jubilación, con la nueva ley de Ordenación de la Enseñanza Media del ministro Ruiz-Jiménez, en septiembre de 1953 su plaza es declarada a extinguir, no habiendo podido ser nombrado catedrático al carecer de la titulación académica imprescindible a tal fin, la de Bellas Artes o de Arquitectura. ${ }^{35} \mathrm{Al}$ poco tiempo sí conseguiría dicho nombramiento, ${ }^{36}$ en virtud de «titulado de Escuela de Bellas Artes» ${ }^{37}$ y «haber obtenido el título de Profesor de "Dibujo" recientemente», de modo que, al término del año natural y a la preceptiva edad de 70 años, accedía a la jubilación y se despedía de la enseñanza oficial como Catedrático Numerario de Dibujo. Igualmente se despedía de sus compañeros de las dos Escuelas de Magisterio, las de Maestras y Maestros, con el agradecimiento de los servicios prestados durante tantos años en ambas Escuelas. ${ }^{38}$

En 1955 abriría una etapa distinta en su actividad con los mismos quehaceres y ninguna obligación laboral. Ya solo a título particular se prestaría a impartir alguna que otra enseñanza si bien más por entretenimiento o compromiso que por voluntad y sin otra consecuencia más al punto de que su hijo Rafael, concertista y docente de Conservatorio, puede considerarse su único discípulo directo. Es entonces cuando, retomando sus vivencias juveniles, despliega gran actividad. Enraizado en un modo conservador de entender la práctica de la pintura y la apreciación artística en general, prolongará su estilo «luminista» hasta prácticamente el final de sus días y en consonancia con la aceptación general por parte de la sociedad, no tanto en atención a su edad y el respeto a su trayectoria de pintor sino en función de una generalizada apreciación conservadora del arte y alejada de las nuevas y no tan nuevas corrientes artísticas.

Cierto es que se le recuerda como pintor, no tanto como educador, y, si en algún momento se alude a la docencia, es más por sus cualidades personales, por su afabilidad, por la entrega desplegada como profesor y su buen hacer. No quedan testimonios suyos escritos al respecto, pues nunca pretendió ser un teorizador, y de los programas que desarrollara en sus centros no parece que fuera más allá del eficaz y grato cumplimiento de los mismos según las normativas por lo que no cabe intuir ni elucubrar al respecto. Su concepción del arte hay que buscarla en su pintura por consiguiente. Pero, y de esto sí llegué a tener testimonios, dejó un entrañable e inmejorable recuerdo entre sus alumnos de la Escuela y del Instituto.

\footnotetext{
${ }^{34}$ Boletín Oficial del Estado de 9 de febrero de 1943.

${ }^{35}$ Boletín Oficial del Estado de 11 de septiembre de 1953.

${ }^{36}$ Boletín Oficial del Estado de 26 de diciembre de 1954.

${ }^{37}$ Dicha titulación oficial, al final de su vida docente, preceptiva a fin de poder jubilarse como Catedrático, la alcanza tras superar las asignaturas que le restaban, a tal fin, en la Escuela Superior de Bellas Artes de Sevilla. ${ }^{38}$ Claustro extraordinario de 17 de diciembre de 1954. AUCA. L-5 EN. 